\title{
Analytical Method for Analysis of Interaction of Retaining Wall Backfilled with Soil under Explosion Loading
}

\author{
Viktoras DOROŠEVAS \\ Kaunas University of Technology, Faculty Civil Engineering and Architecture, Studentu str. 48 -284, Kaunas, Lithuania, \\ E-mail: viktoras.dorosevas@ktu.lt
}

crossref http://dx.doi.org/10.5755/j01.mech.24.1.19448

\section{Introduction}

The problem of estimation of the accidents caused by explosions is one of the most critical challenges for civil engineers today. No country can ignore the accidents hazardous to environment and human. The civil engineering structures such as retaining wall backfilled with soil are the example of retaining structure and are composed of elements with different properties and distinctions. The problem active research for over 90 years due to the abundance and importance of earth retaining structures and the complexity of their dynamic response. The first steps were done by Okabe [1] and Manonobe\&Matsuo [2]. In the past several decades, the Mononobe-Okabe equations have been used extensively for evaluating the magnitude of dynamic earth pressure $[3,4,5,6,7,8,9]$. It should be noted that those equations were developed based on limit equilibrium for cohesionless soil and should be used only for granular soil e. g., sand. If a retaining wall cohesion soil backfill e. g., clay we should to apply result of investigated in analytical studies $[10,11,12,13]$. There are a dimensionless cohesion term (normalized by unit weight and height of the supported soil) is employed.

Interaction between retaining structure and explosive devices can be analyzed with engineering software packages that use finite difference, finite volume and finite element techniques [14], for example AUTODYN, LSDYNA, ABAQUS, however we got a single solution for such problem. The analytical and discrete method allows a thorough studying of the interaction of retaining structure under dynamic loading. For example, pseudo-dynamic method by Steedman and Zeng [15]. But the analytical method also has its own restrictions. The latter is concerned with evaluation of boundary conditions and the selection of suitable analytical description functions. The boundary conditions depend on the retaining structure, so in order to evaluate all its peculiarities, for example, stiffness of separate elements, etc., it is purposeful to use finite difference, finite volume and finite element techniques, and compensating the advantages, which could have been provided by analytical methods with a bigger number of discrete experiments. Such flexible use of mathematical modelling allows a quite fast selection of analytical solution of dynamics problems for express analysis and such, but with particular assumptions and restrictions or allows performing a more comprehensive investigation using software such as AUTODYN.

This paper is intended to present a three-dimensional new analytical method and its application to the dynamic analysis of the retaining wall backfilled with soil interaction under explosion loading. The analytical method effectively simplifies the calculation procedures and is used to study the qualitative changes of the retaining structure under dynamic load. To solve this problem, the following master assignments are to be carried out:

1) Determination of the resulting displacement of backfilled soil under explosion loading;

2) Determination of the active earth pressure to retaining wall under explosion loading.

To verify the reliability of the proposed analytical method, calculations of static active lateral earth pressures were performed with three different types of soil. The theoretical results are compared with the results obtained by the proposed analytical method.

\section{The analytical method}

\subsection{Basic assumptions}

The analytical method is based on the physical model in which the main assumptions are adopted:

1) retaining wall is absolutely rigid and in equilibrium;

2) the strength parameters of retaining wall are known;

3) the soil backfill behind retaining wall is an elastic body with the parameters (density of soil $\rho$, shearing modulus $G$, Poisson's ratio $\mu$ ) known from the physical investigation;

4) the shear modulus of backfilled soil is constant with depth through the backfill;

5) the explosive device subjecting the soil (surface forces) is also known;

6) the external volume (mass) forces were neglected.

Displacements of the elastic soil points $(u-$ in $O x$ direction, $v-O y, w-O z)$ in the Cartesian system $O x y z$ were sought for under the initial conditions:

- at the initial moment the displacements of soil points are equal to zero;

under boundary conditions:

- displacements perpendicular to the retraining wall are equal to zero, thus when $y=a$ on the plane DCC'D', then displacement $v=0$;

on free surfaces of soil, the normal stresses perpendicular to the free surfaces are equal to zero.

Let's suppose that:

$$
u=U q ; v=V q ; w=W q
$$

$U=U(x, y, z) ; V=V(x, y, z) ; W=W(x, y, z) ; q=q(t)$. 


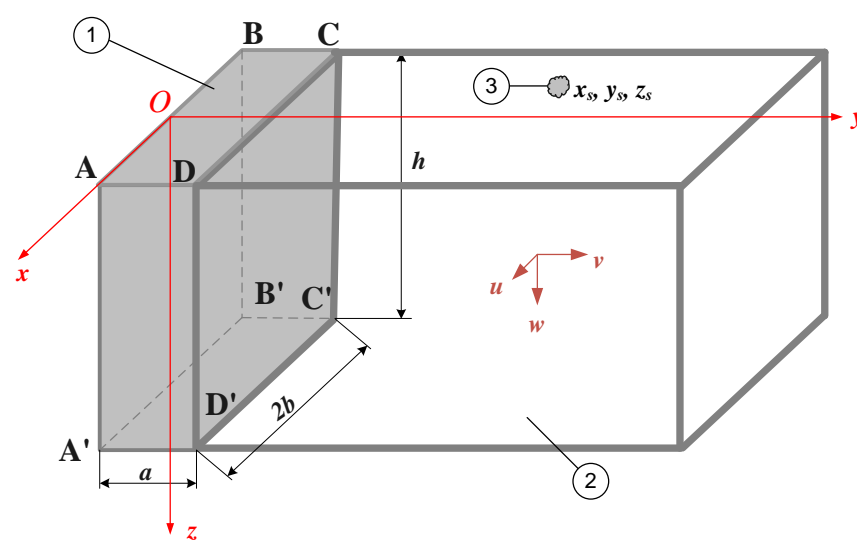

Fig. 1 Example of the structural model: 1 - retraining wall; 2 - backfill soil; 3 - explosive device

Thus functions $U, V$ and $W$ are selected on the basis of the boundary conditions, i. e. they should be fit for a body presented in Fig. 1. Coefficients of the chosen functions $U$, $V$ and $W$ can be found from the condition:

$$
\left.\sigma_{z}\right|_{z=0}=0
$$

In our case for an elastic soil we shall have:

$$
\sigma_{z}=2 G W_{z}+\frac{2 \mu G}{1-2 \mu}\left(U_{x}+V_{y}+W_{z}\right)
$$

where: $U_{x}=\frac{\partial U}{\partial x} ; V_{y}=\frac{\partial V}{\partial y} ; W_{z}=\frac{\partial W}{\partial z}$.

Since calculation is approximate, calculating according to the equation (4) gets an error. To minimize the error, we should calculate the coefficients of the chosen functions, according to the method of orthogonality, for instance.

\subsection{Mathematical model}

In case of explosion loading, we got a mathematical model resulting from Hamilton principle and obtain the following equation:

$$
\begin{aligned}
& -\ddot{q} \rho \iint_{(\Omega)}\left(U^{2}+V^{2}+W^{2}\right) d x d y d z-2 G q \iiint_{(\Omega)}\left\{\begin{array}{l}
\left(U_{x}^{2}+V_{y}^{2}+W_{z}^{2}\right)+\frac{\mu}{1-2 \mu}\left(U_{x}+V_{y}+W_{z}\right)^{2}+ \\
+\frac{1}{2}\left[\left(U_{y}+V_{x}\right)^{2}+\left(U_{z}+W_{x}\right)^{2}+\left(V_{z}+W_{y}\right)^{2}\right]
\end{array}\right\} d x d y d z+ \\
& +\iint_{(S)}(\bar{X} U+\bar{Y} V+\bar{Z} W) d S=0 .
\end{aligned}
$$

where: $U_{y}=\frac{\partial U}{\partial y} ; V_{x}=\frac{\partial V}{\partial x} ; W_{x}=\frac{\partial W}{\partial x} ; U_{z}=\frac{\partial U}{\partial z} ; V_{z}=\frac{\partial V}{\partial z} ; W_{y}=\frac{\partial W}{\partial y}$.

$\Omega$ is integration volume, $i$. $e$. the space part occupied by a soil, $S$ is integration area, $i$. e. the surface part subjected to external surface forces and $\bar{X}, \bar{Y}, \bar{Z}$ are projections of external surface force (area unit is subjected to that force) on co-ordinate axes.

This eq. (5) can be rewritten:

$$
m \ddot{q}+k q=P,
$$

where:

$$
\begin{gathered}
m=\rho \iiint_{(\Omega)}\left(U^{2}+V^{2}+W^{2}\right) d x d y d z, \\
k=2 G \iiint_{(\Omega)}\left\{\begin{array}{l}
U_{x}^{2}+V_{y}^{2}+W_{z}^{2}+ \\
+\frac{\mu}{1-2 \mu}\left(U_{x}+V_{y}+W_{z}\right)^{2}+ \\
+\frac{1}{2}\left[\begin{array}{l}
\left(U_{y}+V_{x}\right)^{2}+\left(U_{z}+W_{x}\right)^{2}+ \\
+\left(V_{z}+W_{y}\right)^{2}
\end{array}\right.
\end{array}\right\} d x d y d z, \\
P=\iint_{(S)}(\bar{X} U+\bar{Y} V+\bar{Z} W) d S .
\end{gathered}
$$

In order to find function $q(t)$ we refer to Eq. (6) and obtain the following integral differential equation:

$$
m \frac{d q}{d t}=-k \int_{0}^{t} q d t+\int_{0}^{t} P d t .
$$

In a case of explosion loading, taking into account that the pressure of explosion products (gas) is the same in all directions $(\bar{X}=\bar{Y}=\bar{Z})$, the impact effect is described by equations:

$$
\begin{aligned}
& \int_{0}^{t} P d \tau=L I, \\
& L=\iint_{(S)}(U+V+W) d S, \\
& I=\int_{0}^{\tau} \bar{X} d t=\int_{0}^{\tau} \bar{Y} d t=\int_{0}^{\tau} \bar{Z} d t .
\end{aligned}
$$

According to Dubnov, L.V., Baharevich, N.S. \& Romanov, A.I [16]:

$$
I=k^{\prime} \sqrt{Q_{v}},
$$


where: $\tau$ is the impact period; $k$ ' is the expansion index; $Q_{v}$ is explosion heat.

In this case, eqn. (10) can be rewritten:

$$
m \frac{d q}{d t}=-k \int_{0}^{\tau} q d t+L I .
$$

After we have calculated the integral coefficients by using the iteration method the approximate solution of Eq. (15) can be obtained:

$$
\begin{aligned}
& q=\frac{L I}{m} \tau-\frac{k L I}{6 m^{2}} \tau^{3}+\frac{k^{2} L I}{120 m^{3}} \tau^{5}-\frac{k^{3} L I}{5040 m^{4}} \tau^{7}+ \\
& +\frac{k^{4} L I}{362880 m^{5}} \tau^{9}-\frac{k^{5} L I}{39916800 m^{6}} \tau^{11}+ \\
& +\frac{k^{6} L I}{6227020800 m^{7}} \tau^{13}-\frac{k^{7}}{1.307674368 \times 10^{12} m^{7}} \tau^{15} .
\end{aligned}
$$

Therefore, displacements determined by the method mentioned above will be considered to be theoretical ones, because it is practically impossible to affect every particle, a mass point, of a soil, i.e., it is impossible to explode a charge at every point of soil space. As it is known Dubnov, L.V., Baharevich, N.S. \& Romanov, A.I [16], the radius of a spherical charge can be given by the weight of the charge:

$$
r \approx \sqrt[3]{G_{u}}
$$

where: $G_{u}$ is the weight of the charge. Suppose that we have chosen a charge of $1 \mathrm{~kg}$ mass. It can be conventionally called a test impulse designated $I_{t}$. Then for the real impulse at point $i$, whose co-ordinates $x_{i}, y_{i}, z_{i}$ and $R_{i}$ are the distance from point $i$ to the real point of charge explosion, which coordinates $x_{0}, y_{0}, z_{0}$, i.e. $R_{i x}=\left|x_{i}-x_{0}\right|, R_{i y}=\left|y_{i}-y_{0}\right|$ and $R_{i z}=\left|z_{i}-z_{0}\right|$ are calculated:

$$
I_{i}=I_{t}\left(\frac{0,1}{0,1+R_{i}}\right) .
$$

In this case, eqn. (16) can be rewritten:

$$
q_{i}=\frac{L I_{i}}{m} \tau\left(\begin{array}{l}
1-\frac{k}{6 m} \tau^{2}+\frac{k^{2}}{120 m^{2}} \tau^{4}-\frac{k^{3}}{5040 m^{3}} \tau^{6}+\frac{k^{4}}{362880 m^{4}} \tau^{8}- \\
-\frac{k^{5}}{39916800 m^{5}} \tau^{10}+\frac{k^{6}}{6227020800 m^{6}} \tau^{12}
\end{array}\right)-\frac{k^{7}}{1.307674368 \times 10^{12} m^{7}} \tau^{15} .
$$

Then for all backfill soil points the real displacement using Eq. (1) are calculated.

Now let's go to the next step of calculation. Therefore the influence of the dynamic processes on the structure of retaining wall should be assessed and the conditions under which the strength of retaining wall is ensured should be determined. In our case (Fig. 1) we have:

$$
\left\{\begin{array}{l}
\cos (x n)=0 \\
\cos (y n)=1 \\
\cos (z n)=0
\end{array}\right.
$$

where: $n$ is the normal to the retaining wall.

Then for calculation of pressure perpendicular to $y$ axis, using the following equations:

$$
\begin{aligned}
& p_{y n}=2 G q\left[\frac{\mu}{1-2 \mu}\left(U_{x}+V_{y}+W_{z}\right)+V_{y}\right], \\
& p_{x n}=G q\left(U_{y}+V_{x}\right), \\
& p_{z n}=G q\left(W_{y}+V_{z}\right),
\end{aligned}
$$$$
p_{\text {oy }}=G q \sqrt{\begin{array}{l}
4\left[\frac{\mu}{1-2 \mu}\left(U_{x}+V_{y}+W_{z}\right)+V_{y}\right]^{2} \\
+\left(U_{y}+V_{x}\right)^{2}+\left(W_{y}+V_{z}\right)^{2}
\end{array}} .
$$

Eventually, making use of equations (1, 16, 24), the active earth pressure to retaining wall can be calculated, and the strength of retaining wall can be introduced by using the known allowable stress $\sigma_{\text {all }}$ of retaining wall structure:

$$
p_{\text {oy }}<\sigma_{\text {all }} \text {, }
$$

where: $\sigma_{\text {all }}$ is allowable stress of retaining wall structure.

\section{Numerical examples}

The problem simulated numerically is sketched in Fig. 1. For example, the geometrical values $a=1 \mathrm{~m}, h=6 \mathrm{~m}$ and $b=10 \mathrm{~m}$. We have three different type of soil with the physical-mechanical parameters know from laboratory test and showing in Table 1.

Firstly, let's suppose that the functions $U, V$ and $W$ are selected on the basis of the boundary conditions (Fig. 1):

$$
\left\{\begin{array}{l}
U=\left(b^{2}+x^{2}\right)(a+y)^{2}\left(z^{2} a+K_{1} y^{3}\right) / a^{7} \\
V=\left(a^{2}-y^{2}\right)(a+z)^{2}\left(x^{2} a+K_{2} y^{3}\right) / a^{7} \\
W=\left[(z+a)^{2}-x^{2}\right](z+h)^{3}\left(a^{2}+K_{3} y^{2}\right) / a^{7}
\end{array}\right.
$$

The coefficients of the chosen functions $U, V$ and $W$ found from the condition (3) and using equation (4) got the error. According to the method of orthogonality calculated the coefficients of the chosen functions and other parameters by Eqs. $(7,8)$. The results are showing in Table 2 . 
Table 1

The physical-mechanical parameters

\begin{tabular}{|c|c|c|c|}
\hline $\begin{array}{l}\text { Type of } \\
\text { soil }\end{array}$ & $\begin{array}{c}\text { Density } \\
\rho\left(\mathrm{kg} / \mathrm{m}^{3}\right)\end{array}$ & $\begin{array}{c}\text { Shear modu- } \\
\text { lus } G(\mathrm{~Pa})\end{array}$ & $\begin{array}{c}\text { Poisson's ratio } \\
\mu\end{array}$ \\
\hline $\mathrm{A}$ & 1835 & $1.0 \times 10^{8}$ & 0.25 \\
\hline $\mathrm{B}$ & 1733 & $0.7 \times 10^{8}$ & 0.3 \\
\hline $\mathrm{C}$ & 1376 & $0.19 \times 10^{8}$ & 0.45 \\
\hline
\end{tabular}

received after an explosion of a spherical ammonite charge of $1 \mathrm{~kg}$ mass in the backfill soil at the position: $x_{0}=0 \mathrm{~m}, y_{0}=3$ $\mathrm{m}, z_{0}=0.1 \mathrm{~m}$. Finally using the parameters from Table 2 . and equations $(14,17$ - 19, 24, 26) we calculated the active earth pressure to retaining wall in the same place (point). So using Matlab we can calculate and to compare results of three cases of soil. Figs. $2-4$ shows the fragments of analytical results for backfill soil pressure distribution along the wall plane under an explosion of a spherical ammonite charge of $1 \mathrm{~kg}$ at same place and time for different type of soil.

Table 2

The parameters for calculation

\begin{tabular}{|c|c|c|c|c|c|}
\hline Type of soil & $K_{1}$ & $K_{2}$ & $K_{3}$ & $m$ & $k$ \\
\hline A & -1.40858 & -10.7942 & -0.0468535 & $3.1207 \times 10^{24}$ & $8.1295 \times 10^{28}$ \\
\hline B & -1.09556 & -8.39546 & -0.0468535 & $1.7829 \times 10^{24}$ & $4.1218 \times 10^{28}$ \\
\hline C & -0.573864 & -4.39762 & -0.0468535 & $3.8844 \times 10^{23}$ & $1.6971 \times 10^{28}$ \\
\hline
\end{tabular}

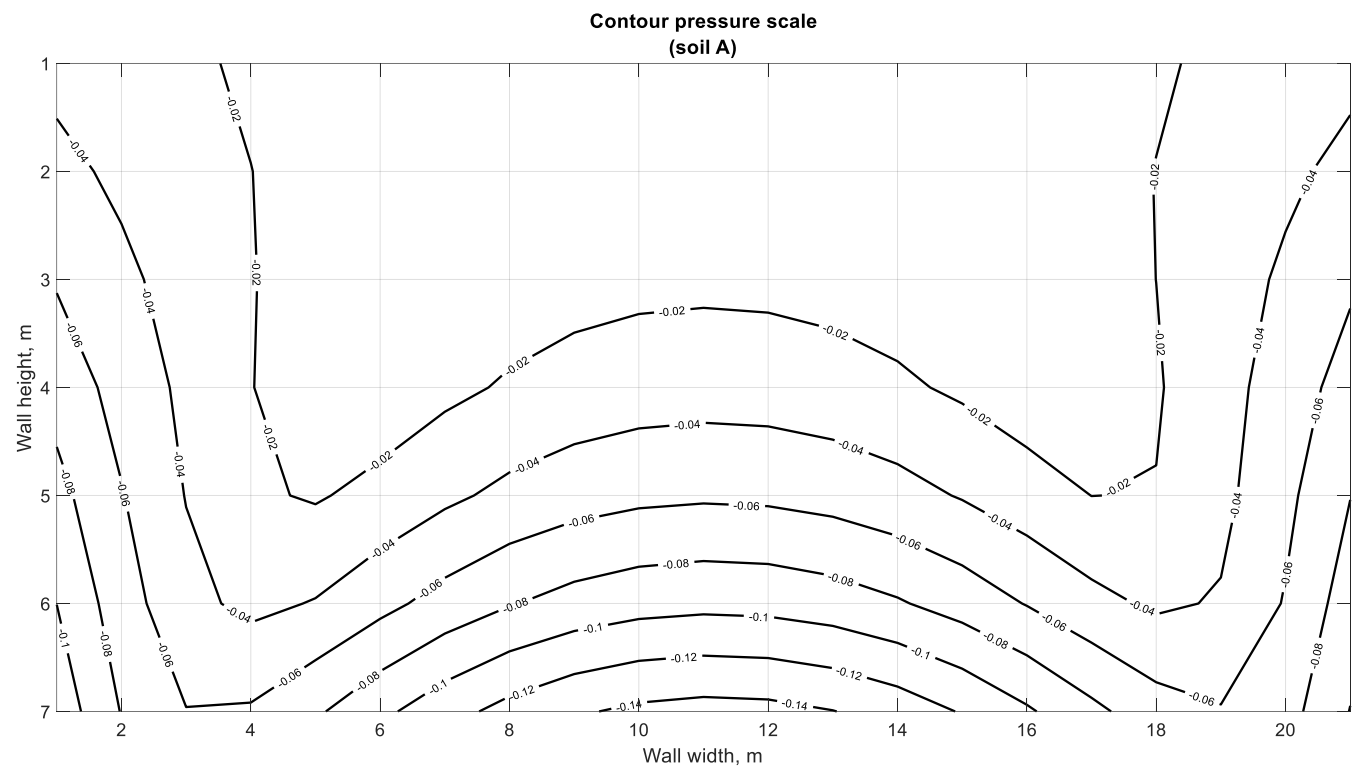

Fig. 2 Fragment of the analytical results for backfill soil A pressure distribution along the wall plane under an explosion of a spherical ammonite charge of $1 \mathrm{~kg}$

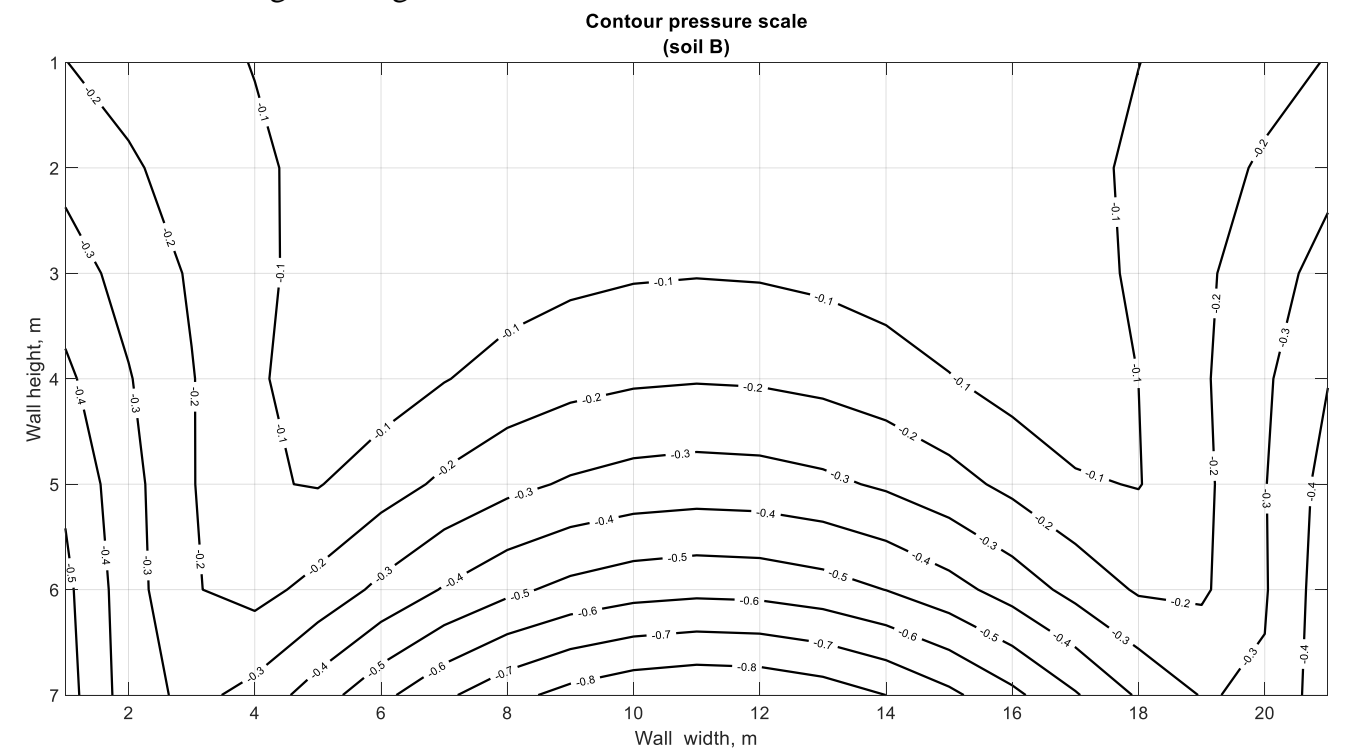

Fig. 3 Fragment of the analytical results for backfill soil B pressure distribution along the wall plane under an explosion of a spherical ammonite charge of $1 \mathrm{~kg}$ 


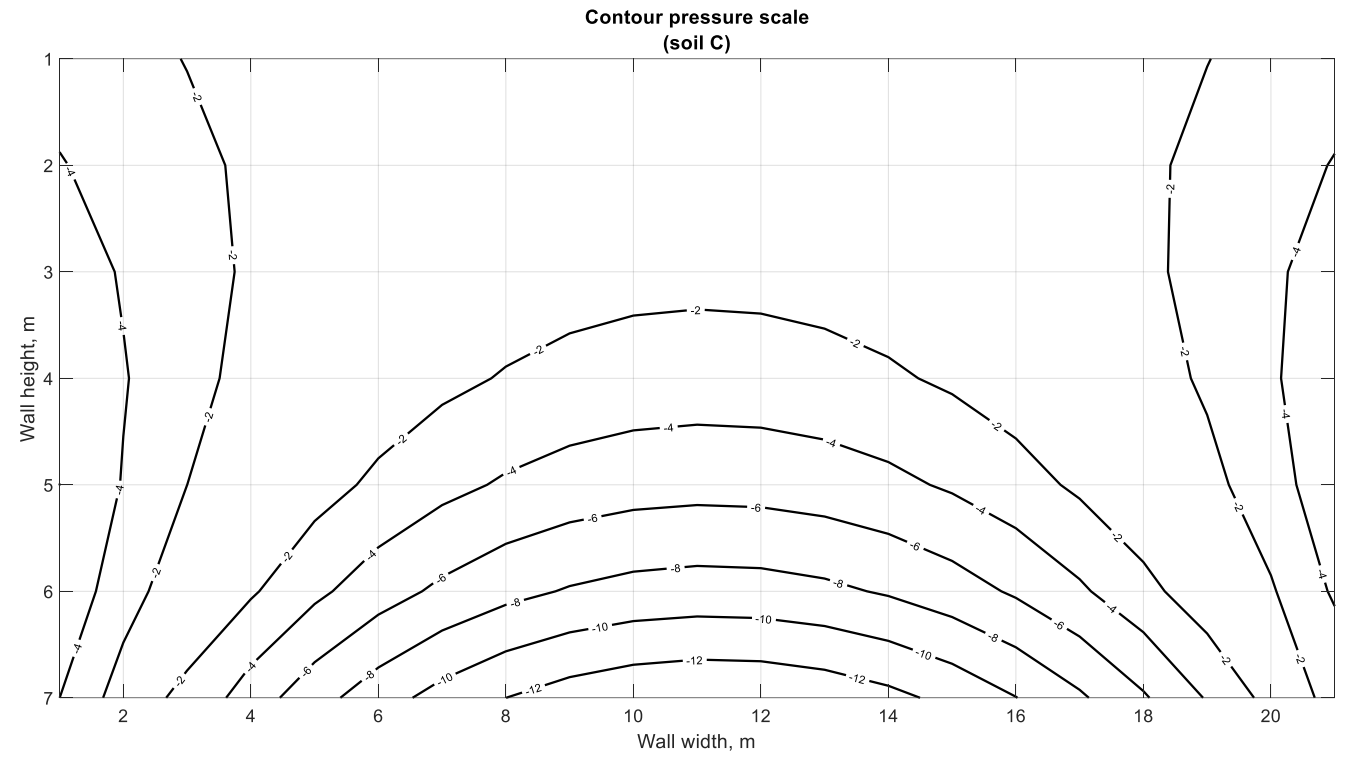

Fig. 4 Fragment of the analytical results for backfill soil $\mathrm{C}$ pressure distribution along the wall plane under an explosion of a spherical ammonite charge of $1 \mathrm{~kg}$

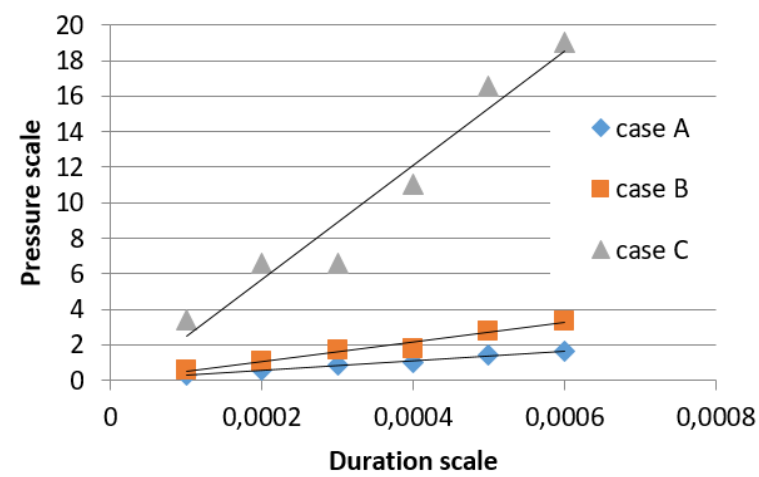

Fig. 5 The active pressure of A, B and C type of soil in the same point of wall dependence by the duration of explosion

If changed the duration of explosion in the Eq. (19) we can get dependence the active pressure by time in the same point of wall and this relation can be describing the linear as shows in the Fig. 5.

\section{Conclusions}

bles:

Developed and presented analytical method ena-

- to study the interaction between the retaining wall and different backfill soil under explosion loading and determine influences to the retaining wall;

- to establish functional dependence between different physical-mechanical parameters of same structural model and explosion loading;

- to evaluate consequences of explosion in the retraining wall structures.

\section{References}

1. Okabe, S. 1926. General theory of earth pressure, Journal of the Japanese Society of Civil Engineers, Tokyo, Japan, 12(1): 123-134.
2. Mononobe, N. and Matsuo, H. 1929. On the determination of earth pressure during earthquakes, Proceedings, World Engineering Conference, vol. 9: 176.

3. Koseki, J; Tatsuoka, F; Munaf, Y; Tateyama, M; Kojima, K. 1998. A modified procedure to evaluate active earth pressure at high seismic loads. Spec Issue Soils Found Jpn Geotech Soc: 209-216. https://doi.org/10.3208/sandf.38.Special_209.

4. Gazetas, G; Psarropoulos, P; Anastasopolous, I; Gerolymos, N. 2004. Seismic behaviour of flexible retaining systems subjected to short-duration moderately strong excitation. SoilDynEarthqEng; 24:537-50. https://doi.org/10.1016/j.soildyn.2004.02.005.

5. Al Atik, L; Sitar, N. 2010. Seismic earth pressures on cantilever retaining structures. J GeotechGeoenvironEng, 136 (10):1324-33. https://doi.org/10.1061/(ASCE)GT.19435606.0000351.

6. Earth Mechanics 2005. Inc. Field investigation report for abutment backfill characterization. UCSD Report No. SSRP-05/02. San Diego, La Jolla, CA: Department of Structural Engineering, University of California.

7. Giarlelis, C; Mylonakis, G. 2011. Interpretation of dynamic retaining wall model tests in light of elastic and plastic solutions. SoilDynEarthqEng, 31:16-24. https://doi.org/10.1016/j.soildyn.2010.07.002.

8. Shamsabadi, A; XuShi-Yu, Taciroglu E. 2013. A generalized log-spiral-Rankine limit equilibrium model for seismic earth pressure analysis. SoilDynEarthqEng, 49: 197-209.

http://dx.doi.org/10.1016\%2Fj.soildyn.2013.02.020.

9. Sitar, N; Geraili Mikola, R; Candia, G. 2012. Seismically induced lateral earth pressures on retaining structures and basement walls. Keynote Lecture, Geotechnical Engineering State of the Art and Practice, Keynote Lectures from Geo Congress 2012.GSP226, ASCE; 2012.

10. Saran, S; Prakash, S. 1968, Dimensionless parameters for static and dynamic earth pressures behind retaining walls, IndianGeotechJ1, 7(3):295-310. 
11. Richards, R; Shi, X. 1994 Seismic lateral pressures in soils with cohesion, JGeotech Eng, 120(7): 1230-51. https://doi.org/10.1061/(ASCE)07339410(1994)120:7(1230).

12. Shukla, S; Gupta, S; Sivakugan, N. 2009. Active earth pressure on retaining wall for $\mathrm{c}-\phi$ soil backfill under seismic loading condition, JGeotechGeoenvironEng; 135(5): 690-6. https://doi.org/10.1061/(ASCE)GT.19435606.0000408 .

13. Vahedifard, F; Leshchinsky, B, A; Sehat, S; Leshchinsky, D. 2014. Impact of cohesionon seismic design of geosynthetic-reinforced earth structures, JGeotechGeoenviron Eng, 140(6):1-12. https://doi.org/10.1061/(ASCE)GT.19435606.0001099.

14. Wu G, WDL Finn. 1999. Seismic lateral pressures for design of rigid walls. Can GeotechJ, 36:509-22. https://doi.org/10.1139/t99-013.

15. Steedman, R.S. and Zeng, X. 1990. The influence of phase on the calculation of pseudo-static earth pressure on a retaining wall, Geotechnique, 40(1): 103-112. https://doi.org/10.1680/geot.1990.40.1.103.

16. Dubnov, L.V; Baharevich, N.S. \& Romanov, A.I. 1973. Industrial explosive substances, Nedra, Moscow, 120-190.

\section{Doroševas}

\section{ANALYTICAL METHOD FOR ANALYSIS OF \\ INTERACTION OF RETAINING WALL BACKFILLED WITH SOIL UNDER EXPLOSION LOADING}

S u m m a r y

Knowledge of dynamic active soil pressure behind retaining wall is very important in the design and maintenance stage of retaining wall. Dynamic load might cause permanent deformation of retaining structures and even failures with disastrous physical and economic consequences.

This paper presents the analytical method that allows calculating the displacements of backfilled soil under explosion and determining the influence to the retaining structure. The estimation method was realised with different backfill soil of active earth pressure to retaining structures under dynamic load. Results are provided in a tabular and graphical form with a comparison to the pressure at the same point of different backfill soil influences to retraining wall under the same explosion loading.

Keywords: analytical method, retaining wall, active soil pressure, explosion, dynamic analysis.

Received November 09, 2017 Accepted February 15, 2018 